\title{
Managing for Outcomes: Understanding Clients
}

\author{
Bill Ryan
}

Is 'managing for outcomes' (MFO) working? It is interesting that people are starting to ask the question, yet, as always, evaluative answers depend on the prescribed objectives and the time allowed for realising them. I'm not sure that the question can yet be answered, but it is possible to talk about some areas of recent learning.

In my view, the shift towards MFO is profoundly important, not just in New Zealand but also across public management and governing more generally in other parts of the world. If the 'new public management' reforms of the 1980s and 90s were primarily focused on improving the economy, efficiency and accountability (narrowly defined) of the state sector, the recent adoption of 'managing for outcomes' represents a desire to go to the next stage. It is not hard to see this as a long run process of collective learning. To use a metaphor, if the 1980s and 90s were about replacing a worn out machine or system and tuning up the new one, we then asked whether this flash new machine was taking us anywhere. By the end of the 20th century there seemed to be widespread agreement that significant gains had been made in relation to system improvement in New Zealand and elsewhere but that more - quite a bit more - needed to be done in relation to the broader issue of 'governing' (Schick, 1996; see also OECD, 2005). So, in New Zealand, we underwent the Review of the Centre (MAG, 2001), amongst other things, and subsequently acquired 'managing for outcomes'.

In adopting MFO, it can be argued that we have gone beyond an obsession with the means of governing - i.e. the public management system (something which particularly applied to New Zealand) - and are turning attention once again to the ends: i.e. the impacts and effects of public policy. In that respect, MFO in New Zealand attempts to preserve the best of managing for outputs, the strengths of the budgeting and financial management system created, whilst asking for - as Scott
(2001) suggests - 'delayed' questions about whether government policy goals and objectives are actually being achieved, presumably in some way better than in the past.

It is this (re)learning that is important: that management has no purpose beyond policy and that policy relies on management for effect. 'Managing for outcomes' asks whether state sector agencies are being managed in such a way that the changed states of national and local affairs desired by the duly elected government of the day, the goals and objectives specified in a welter of policies and strategies large and small, are actually emerging. The focus is increasingly on whether the state sector, as part of the executive and in partnership with the political arm, is acting effectively, appropriately and responsibly in governing the society, and much less the technicalities of its functioning, as was the case in the previous decades. In this sense, it is possible to see the period of 'new public management' as a 'first wave' of reform, the review of which (in New Zealand, the Schick report and the Review of the Centre) has set off a 'second wave' which is likely to take several years to reach a crest (Ryan, 2003a; SSC, 2003; see also OECD, 2002; 2005).

As this new concern with outcomes emerges, however, despite the reassuring words in the opening pages of the Review of the Centre report (MAG, 2001, e.g. pp.4, 14) it can also be argued that managing for outcomes is a reform agenda based on much more than mere tinkering. The more its logic is plumbed - in theory - anyway, the more it seems to demand significant modification of some fundamental aspects of prescribed and enacted practice: e.g. the minister-official-client relationship; networks not bureaucracies; engagement not disinterestedness; facilitation not command (Ryan, 2003b). In that respect, therefore, this second wave is likely to be highly recursive in character, with critical shifts in the constitutional, governance and management 
frameworks within which state servants work and play (which are likely to coincide with and contribute to future debates around the formation of a republic).

This is partly why managing for outcomes is proving very difficult. Its logic can foreground certain constitutional tensions (e.g. The minister says this, we say that, the evidence is on our side - and the stakeholders agree - so, if we're supposed to be focusing on making a difference, what are we to do?'). It is also intellectually and politically challenging (e.g. 'It's hard and laborious defining our contributing outcomes and even more to attribute changes to our strategies'; 'Other agencies and stakeholders see things differently and it's hard to get consensus').

In truth, though, the full extent of the challenge is only just now being realised. One aspect of this relates to our understanding of societal change, of how it occurs, and the role in it that governments and policy might or might not play. I suggest that, in the theory of public management and public policy - and when I say 'theory' I include the applied theorising found in state sector plans and strategies - our understandings are at an early stage of development. The practice (tacit practice, enacted practice and embedded routines) might contain more know-how, but, in this article, I will focus on documented plans and strategies.

\section{MFO, outcomes and causality}

A critical part of the MFO approach for agencies revolves around identifying the ultimate outcomes sought by government, then figuring out the lower-level outcomes that will contribute to them. These will be 'contributory' outcomes in the sense that they will be one dimension or component of the overall outcome. The current government priorities are:

\section{Economic Transformation}

working to progress our economic transformation to a high income, knowledge based market economy, which is both innovative and creative and provides a unique quality of life to all New Zealanders;

The economic transformation theme can usefully be approached using the following sub-themes:

- growing globally competitive firms;

- $\quad$ world class infrastructure;
- innovative and productive workplaces, underpinned by high standards in education, skills and research;

- an internationally competitive city Auckland;

- $\quad$ environmental sustainability;

\section{Families - young and old}

all families, young and old, have the support and choices they need to be secure and be able to reach their full potential within our knowledge based economy;

Families, young and old theme can usefully be approached using the following sub-themes:

- $\quad$ strong families;

- $\quad$ healthy confident kids;

- $\quad$ safe communities;

- $\quad$ better health for all;

- $\quad$ positive ageing;

\section{National Identity}

all New Zealanders to be able to take pride in who and what we are, through our arts, culture, film, sports and music, our appreciation of our natural environment, our understanding of our history and our stance on international issues;

National identity theme can usefully be approached using the following sub-themes:

- $\quad$ who we are;

- $\quad$ what we do;

- $\quad$ where we live;

- $\quad$ how we are seen by the world;

Departments should take these themes into account in all their planning processes and consider how core business and baselines can be aligned to support the three priority themes and, as appropriate, be expressed in Statements of Intent. (DPMC, 2006)

The Statements of Intent (SOIs) for 2006 reveal the ways in which agencies believe they contribute to any or all of these goals. In relation to 'Families - young and old', the Ministry of Education, for example, says that: 
Education will support initiatives aimed at raising achievement and reducing disparities, and initiatives aimed at strengthening family functioning and capability. (MinEdu, 2006, p.10)

The Ministry of Social Development contributes extensively across a range of fronts:

The Ministry's policy, research, and services for children, families, communities, and older people all contribute towards the priority of families - young and old. We provide quality services to all families, including families experiencing particular difficulties; lead government work to reduce and prevent family violence; fund and support the community organisations that provide local services; and work across government to ensure that all the policies that affect families, like health, education, and positive ageing, work well together. (MSD, 2006, p.27)

\section{The Department of Internal Affairs says:}

The Department's involvement with families starts with the registration of births, marriages, civil unions and deaths. Families are also supported directly by our community development work, our support for volunteering, our censorship work, and our work with communities and local government to control gambling. (DIA, 2006, p.8)

The Ministry of Justice (2006, p.14) contributes through 'safer communities' and a 'fairer, more credible and more effective justice system'.

If these outcomes are contributory in a whole-ofgovernment sense, other, lower-level outcomes are logically or causally prior outcomes in the sense of preconditions that need to be achieved before the ultimate outcomes can emerge (referred to in New Zealand as 'intermediate outcomes'). Alternatively, they may be conceptualised as correlations, as multiple, interconnected factors that must be present for the outcomes to emerge. The Ministry of Education, for example, has identified several factors it must work on to achieve its contributory goals. One of several the ministry identifies is 'effective teaching' (MinEdu, 2006, p.10). The State Services Commission identifies, amongst other things, its 'people capability' strategy as critical to achieving its state sector development goals (SSC, 2006, p.23). The Ministry of Health has been working for some time on system development goals, referred to as 'Developing and Maintaining our Capability' (MoH, 2006, p.68ff).

According to the theory, agency strategies - the activities the agency will undertake in order to achieve these outcomes, and undertake precisely and only because the agency believes they will cause these outcomes to emerge - should be underpinned by a causal model: in New Zealand, referred to as 'intervention logic'. Many positive and negative things can be and have been said about intervention logic (e.g. about the term 'intervention' itself; about outcomes hierarchy vs. causal chain approaches; strengths and weaknesses; technocratic vs. heuristic application; and the manner of its design, introduction and implementation), but I still take the idea as being a useful and necessary heuristic (Ryan, 2002). MFO stands or falls by whether agencies have some definite conception, whether in theory or practice, of the causal or generative mechanisms whereby their goals and objectives will emerge and their role in ensuring that they do. Making these models explicit in plans and strategies is therefore important, for clarity, to ensure that staff, providers and associated agencies understand their role in the collective effort, and for the purposes of evaluation and accountability.

In the course of identifying these models, agencies therefore should be asking deep and meaningful questions about how they must act, as agents of change, in order to bring about the desired states of affairs. The answers selected, represented as a model, should specify exactly how those desired changes will occur - will actually cause those changes to occur, and not just some vague assertion that, if $\mathrm{X}$ is done, $\mathrm{Y}$ will follow - and these should be apparent to a greater or lesser degree in plans and strategies.

At the very least, then, under an MFO framework agencies should be:

- identifying their high-level contributory goals and objectives;

- figuring out and selecting a detailed and elaborated model they intend employing to create the changes desired; and

- explicitly using the model to develop strategies to be implemented over time to progressively realise intermediate goals and objectives. 
Are they doing so? Are there signs of development of such models underpinning their strategising? Given that the SOIs produced by New Zealand government agencies are a critical part of the budget process and all agencies have now been producing them for at least a couple of years, these documents are a reasonable place to look for evidence.

\section{Patchiness and gaps}

Recent SOIs and other strategies suggest that the answer to the questions posed above is something like: 'Sometimes, but the picture seems patchy'. Many documents now reveal attempts to draw connections between 'overall government priorities', 'agency/strategy goals and objectives' and 'planned activities over the next one/two/however many years'. Juxtaposed thus, causal connections are implied. On the surface, all seems valid and plausible. Agencies are pursuing reasonable-looking strategies, and government, parliament and citizens can o tensibly expect, after a while, that the desired objectives and higher-level goals will emerge.

Some agencies seem to be doing more than this and have devised a more explicit model of change to underpin their efforts; indeed, in some cases the model is embedded in the name given to strategies to achieve contributory and intermediate outcomes (as noted above). Work and Income, for example, is employing 'case management' as a key strategy for dealing with long-term unemployed (MSD, 2006, p.59); Inland Revenue (IRD, 2006, p.25) and Customs (2006, p.5) are explicitly pursuing 'voluntary compliance' models; the Ministry of Education sees one of its critical strategies as 'effective teaching' (2006, p.10); Corrections has been pursuing 'offender management' approaches (2006, p.19); the Ministry of Health, charged with implementing the complex Primary Health Care Strategy, is focusing on several elements, of which one is a model of 'system development', as critical to the overall success of the strategy, using the SSC state sector development goals as a management lens (MoH, 2006, p.68).

Some of the SOIs seem to present a comprehensive and thoughtful picture of what the agency is trying to achieve and how. For example, following on from the point made above in relation to 'effective teaching' as a contribution to the overall well-being of families, the Ministry of Education SOI says:
We need teaching that works for New Zealand students who come to school:

- with increasingly varied prior knowledge and experience

- speaking a range of languages

- at a range of achievement levels

- with fluid and complex ethnic and social cultures and heritages

- bringing varied abilities and cultural resources to their learning.

Teachers can increase their focus on raising student achievement and reducing disparity through involvement in strong learning professional communities, and by participating in ongoing professional learning. (MinEdu, 2006, p.29)

The document goes on to define 'effective teaching' in terms of:

The Best Evidence Synthesis: Quality Teaching for Diverse Students identifies the key characteristics of effective teaching in the schooling sector and how these contribute to better outcomes. From this and other sources we know that educators who are effective:

- are focused on student achievement and expect and achieve high standards of outcomes for all their learners

- know their curriculum material or subject and how to teach it and understand the general principles of learning and those specific to their subject or curriculum material

- use achievement information and evidence to understand their learners and adapt their teaching practices

- respond flexibly and appropriately to the needs of all learners

- build purposeful and productive relationships with learners, peers, family and the community

- link their teaching to the prior knowledge, cultural beliefs and experiences, and learning processes of their learners in different contexts

- are supported by employment and workplace conditions that are enabling and encouraging. (MinEdu, 2006, p.30) 
There is a clear recognition here that effective teaching is also flexible teaching based on an understanding of particular types of students and adaptations in pedagogy to meet their needs. This goes well beyond the vague assertion of connection between overall government goals and agency strategies, to specifying some of the key conditions that must be created and accounted for in actually achieving those goals.

Similar kinds of developments can be found in the current Ministry of Social Development (Work and Income) SOI. For example, at one point in the discussion of outcomes for 'Working age people' (2006, p.58), the following diagram appears. It shows that, whilst the desired outcomes for particular clients (some form of sustainable employment) will define the services provided, the starting point is the assessment of client capabilities, based on which the client will then receive services such as job matching, referrals to other services, work retention, advancement or income support.
Below this diagram the SOI lists some key principles the ministry believes should be paramount in case managing clients:

- The Right Job At The Right Time, Right From The Start

- Work For Those Who Can, Security For Those Who Can't

- Planning For Work As Circumstances Allow

The discussion continues by identifying the results the ministry wants to see:

Working age people are a large and diverse client group and we need a range of measures to identify how well we are achieving our high-level outcome. The results we want to see from our work are that:

- job seekers achieve sustainable employment

- all our working age clients (working age students,

\section{ENHANCED WORK FOCUSED SERVICES}
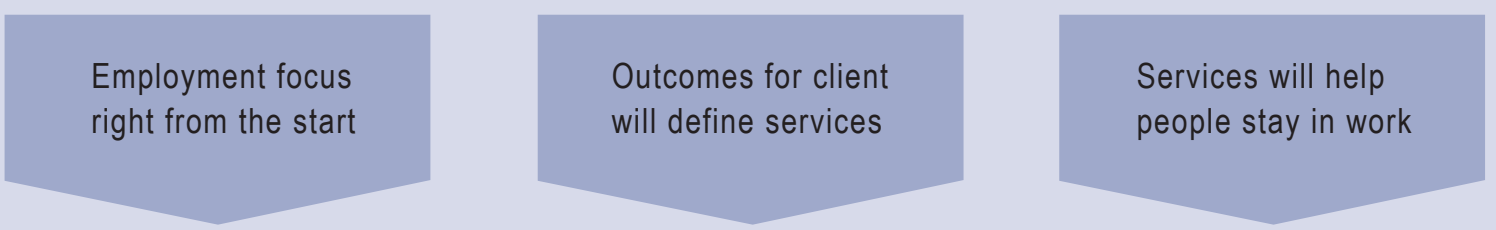

Starting point: assess client capabilities and outcome goal
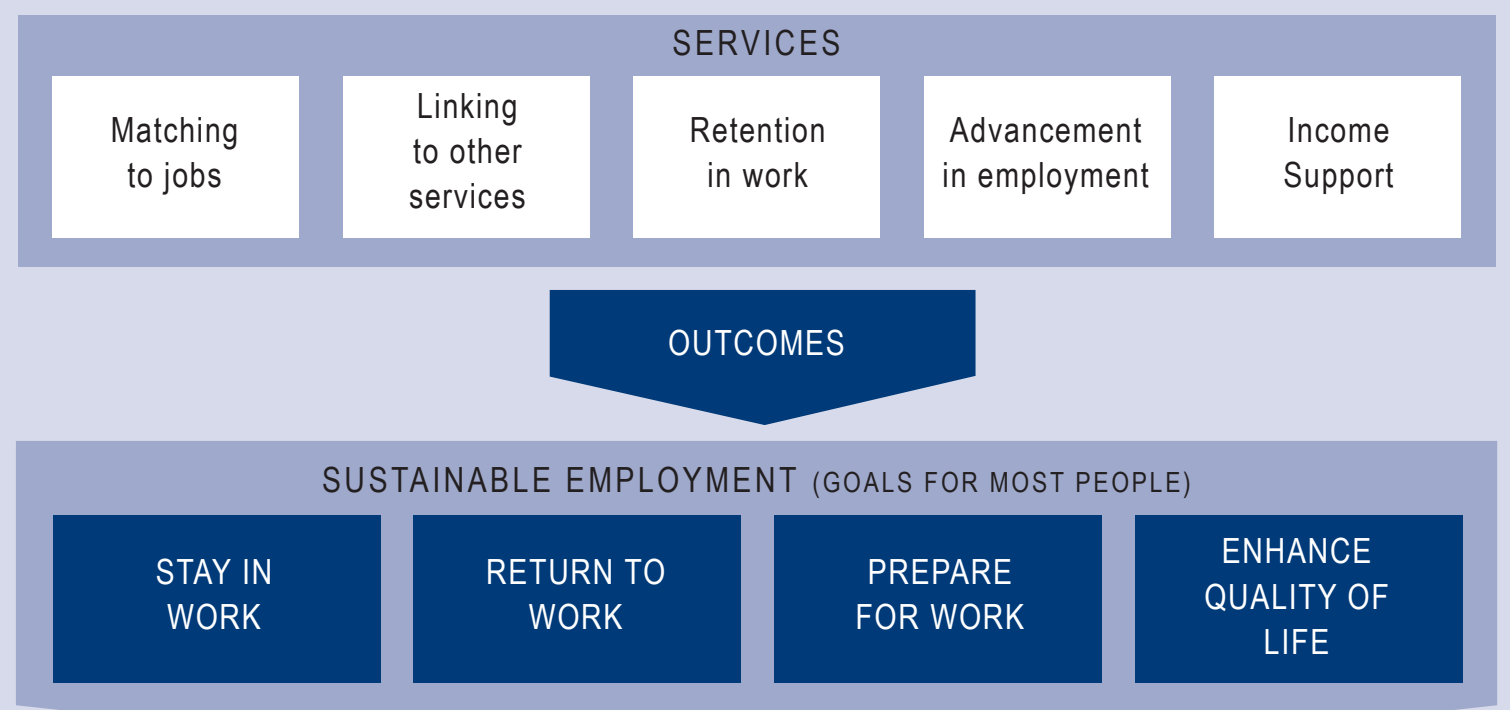

INCREASED PARTICIPATION AND INDEPENDENCE (GOAL FOR EVERYONE) 
beneficiaries, and working people) get the financial support they are entitled to

- our clients are aware of all their entitlements, including entitlements while working and leading up to and during retirement

- benefit fraud is prevented and/or detected early

- the debts of beneficiaries and former beneficiaries are minimised, and their debts are managed accordingly. (MSD, 2006, p.60)

These statements are less focused than the Mininstry of Education instances above on specifying exactly how client needs must drive implementation and design strategies. They also tend to define clients as abstract objects, the subjects of agency strategies. Nonetheless, there are clear signs of sensitivity to the differing circumstances in which various groups of clients find themselves. The interesting thing, though, is that even the Ministry of Education example lacks something in this respect; for all its sophistication, it is still speaking of the qualities to be brought to teaching rather than the learning processes that different types of students will undergo (or not undergo, according to their motivations) - and, hence, what, how, where, when and why the learning outcomes will or will not be achieved. It is not actually a discussion of learning and achievement (the realisation of outcomes) but of the qualities of teaching and classroom strategies (the necessary preconditions of those outcomes). It seems to me that the former must be the actual focus of attention if MFO is to really work.

This, then, seems to be a gap in many agency documents. There is little detail regarding the when, where, why, how and what of what occurs between agency staff carrying out the specified activities and the generation of the desired outcomes: there is a 'black box' in many agency plans and strategies between planned agency action and societal effect. There is little apparent understanding of who and what 'the client' is or how, why and when they act as they do - actual clients, real people, not just the pre-defined subjects of official abstraction who, it is presumed, will act as specified. Understanding clients as real people, their actual needs and actions, where, when, how, why and what they do with agency outputs once they have accessed them and taken them up and used them in some way (or have ignored or subverted them), is critical to the success of any focus on outcomes.
This realisation is not new. Schneider and Ingram (1990) some while ago argued that too little attention is paid in public policy and management to the 'behavioural assumptions of policy tools'. Similarly, Richard Rose (1989) suggested that, for policy to be 'effective', it is critical to understand the role of 'ordinary people in the policy process'. The recent emphasis on understanding the 'co-production' of outcomes (OECD, 2001, pp.412) registers the same point. I, too, have previously argued along the same lines (Ryan, 2003b).

Beyond the examples examined in this paper, the general significance of the point for MFO can be demonstrated by reversing the usual tendency in public management and policy to see things from the top down and looking at things from the client/citizen perspective (and using Elmore's (1979-80) 'backwards mapping' approach). For the desired outcomes to emerge, clients must, in some way, 'use' or otherwise act in relation to the agency outputs. Do they do so? If so, how, why, where and when? On what basis are they motivated to do so? In what manner, form, time and place are they able to access the outputs? How are the outputs (indeed, the whole policy or strategy) presented to them? How do they appear? What value are they made to represent? Do those representations square with the intended clients' values, knowledge sets and frameworks of meaning, from their own preferences and sense of identity up to their (implicit or otherwise) theory of the state? And taking all these considerations together, how do different (sub)groups of clients respond and why?

An additional, parallel set of questions can be asked in relation to (a) targeted clients who do not respond in the manner expected; (b) other actors and agents involved in policy development and implementation; and (c) the actions of the opponents of the policy who will seek to undermine and subvert it, since the actions of these agents will also contribute to the actual outcomes. Any agency strategies devised without recognising these questions in the course of planning, development and implementation are unlikely to succeed (other than by good fortune). The apparent absence of any such awareness or understanding in most agency documents produced under 'managing for outcomes' raises questions about how much progress is occurring in making policy and management more effective - the prime purpose behind the MFO movement. 
The last point to make is that it does not matter whether the policy is founded on the application of authority, the introduction of incentives, or capacity building, is symbolic and hortatory, or makes the assumption of ongoing collective learning (Schneider and Ingramm 1990), or the theory of client action in response to policy is based on any or all of behavourist, humanist, structurationist, psychological, economic or sociological assumptions. The point is that whatever strategic choices are made by an agency, these could or should be apparent to a greater or lesser extent in the detail of the agency plan. The work now being done by the Ministry of Education, the Ministry of Social Development and others seems to confirm the theoretical point.

\section{Conclusion}

The introduction of managing for outcomes is an important recent development in the journey of improving the quality of governance that commenced internationally in the late 1970s and in New Zealand from the late 1980s, a development that is too important for us not to devote considerable attention to its emergence. For various reasons, some good and some bad, MFO was introduced in this country with little fanfare and was represented as no more than an 'evolution' of the so-called 'New Zealand model of public management'. Not all were convinced by that assertion and, indeed, as practitioners and researchers delve further into what MFO might mean it seems increasingly that it really does represent a significantly different and more demanding approach to public management.

For my own part, I have argued elsewhere (Ryan, 2003b) that if we break the notion down into 'planning for outcomes', 'implementing for outcomes', 'resourcing outcomes', 'accounting for outcomes' and so on, we begin to see various ways in which MFO does indeed go beyond past and current ways of working and imply quite different - sometimes radically different - approaches to the work of officials. This paper has attempted to explore a detailed aspect of that same set of issues regarding the realisation and generation of societal change through policy and management. It is apparent from logical deduction, confirmed in practical developments taking place in those agencies where one would expect to see the greatest degree of change (because they are in constant contact with direct clients), that much more needs to be done in understanding and articulating why, how, where and when desired and anticipated change might occur. This requires deeper and more sophisticated understandings of the ways in which clients and citizens respond to particular outputs in co-producing the actual outcomes: i.e. the behavioural aspects of policy development, implementation and the utilisation of government outputs. Understanding clients in this respect is essential for MFO. Glossing over the details will not do. Vague assertions (or relabelling current practices with the language of MFO) makes plans and strategies seem like no more than discursive window-dressing.

Obviously, for the sake of public accountability, to say nothing of clarity and coordination through organisations and policy networks, planning and strategy documents can and should, up to a point but not beyond, be detailed and explicit (wherever that point is, this analysis suggests that it has not yet been reached). On the other hand, it is worth noting that sometimes plans and strategies are precisely 'discursive window dressing': pretty words and evocative images. This is not always a cynical view but a realistic assessment, ultimately, of how such documents are simplifications, representations designed for other purposes - as the surrealist painter René Magritte reminds us - not the reality to which they refer ('Ceci n'est pas une pipe', The Treachery of Images, 1928-29; cf. also Mintzberg, 1994). The reality of policy, of 'managing for outcomes', is to be found in the actions and interactions occurring between front-line staff/providers and clients - in other words, it is located in implementation and delivery and the use that clients make of government outputs. This is where it counts. This is where we should look for a deep practical and theoretical understanding of clients, the purpose and manner of their responses to policy, their co-production of the actual outcomes, and the recursive feedback over time of that expertise and know-how back into policy design, development and advising. This is where we must look and where we must direct attention if MFO is to work. Is this what is expected of officials at the front line? Is that how they act? Do analysts and managers, especially those doing the work of policy design and development, understand this point? There is no systematic answer to these questions; some evidence says 'yes', other evidence says 'no'. I suspect that one answer might be 'Too few'. At this time, there is probably no more important empirical 
question to be explored as we come to understand and learn more about MFO.

\section{References}

Corrections (2006) Statement of Intent 1 July 2006-30 June 2007, Wellington: Department of Corrections

Customs (2006) Statement of Intent 2000-07, Wellington: New Zealand Customs Service

DIA (2006) Statement of Intent 2006-2009, Wellington: Department of Internal Affairs

DPMC (2006) 'Government Priorities', http:// www.dpmc.govt.nz/dpmc/publications/governmentpriorities.html, Department of the Prime Minister and Cabinet, accessed 10 November 2006

Elmore, R. (1979-80) 'Backward Mapping: implementation research and policy decisions', Political Science Quarterly, 94 (4), Winter, pp.601-6

IRD (2006) Statement of Intent 2006-2009, Wellington: Inland Revenue Department

Justice (2006) Statement of Intent 1 July 2006 - 30 June 2007, Wellington: Ministry of Justice

MAG (2001), Report of the Ministerial Advisory Group on the Review of the Centre, presented to the Ministers of State Services and Finance, November, Wellington: Ministerial Advisory Group

MinEdu (2006) Educate: statement of intent 2006-2011, Wellington: Ministry of Education

Mintzberg, H. (1994) The Rise and Fall of Strategic Planning, Hemel Hempstead: Prentice Hall

$\mathrm{MoH}$ (2006) Statement of Intent 2006, Wellington: Ministry of Health

MSD (2006) Moving Forward with Confidence: statement of intent 2006, Wellington: Ministry of Social Development

OECD (2001) Citizens as Partners: information, consultation and public participation in policy-making, Paris: OECD

OECD (2002) Public Sector Modernization: a new agenda, GOV/PUMA (2002) 2, Paris: OECD

OECD (2005) Modernising Government: the way forward, Paris: OECD

Rose, R. (1989) Ordinary People in Public Policy: a behavioural analysis, London: Sage

Ryan, B. (2002) 'Beyond intervention logic? A public management heuristic for the 21st century', paper presented to the Association for Public Policy Analysis and Management 24th annual research conference, Dallas, Texas, 7-9 November

Ryan, B. (2003a) 'Harder yards ahead: the second stage of public sector reform in New Zealand', International Review of Public Administration, 8 (1), July

Ryan, B. (2003b) Learning MFO: managing for outcomes - the Queensland case, report prepared for the Institute of Public Administration Australia

Schick, A. (1996) The Spirit of Reform: managing the New Zealand state sector in a time of change, report prepared for the State Services Commission and the Treasury, New Zealand, Wellington: State Services Commission

Schneider, A. and H. Ingram (1990) 'Behavioral assumptions of policy tools', Journal of Politics, 52 (2), May, pp. 510-29

Scott, G. (2001) Public Management in New Zealand, Canberra: Centre for Law and Economics, ANU

SSC (2003) 'Getting better results - progress report March 2003', extract from the March monthly report from the State Services Commission to the minister of state services, 7 April 2003, http://www.ssc.govt. $\mathrm{nz} /$ display/document.asp?NavID $=105 \& \mathrm{DocID}=3161$, accessed May 2003

Bill Ryan is the Programmes Director in the School of Government,

Victoria University of Wellington. He has been a constant observer of and occasional participant in the reform of Australasian public services since the late 1980s. Most of his present work is based on the suspicion that the 21 st century is emerging as very different from the 20th in many important respects, and will require new ways of governing. 